\title{
Optimization of scanning electron microscope technique for amniotic membrane investigation: A preliminary study
}

\author{
Saaid Al Shehadat ${ }^{1}$, Mehmet Omer Gorduysus ${ }^{1}$, Suzina Sheikh Abdul Hamid ${ }^{2}$, \\ Nurul Asma Abdullah ${ }^{3}$, Abdul Rani Samsudin ${ }^{4}$, Azlina Ahmad ${ }^{5}$
}

Correspondence: Dr. Saaid Al Shehadat

Email: salshehadat@sharjah.ac.ae

\begin{abstract}
'Department of Preventive and Restorative Dentistry, College of Dental Medicine, University of Sharjah, Sharjah, UAE,

${ }^{2}$ Tissue Bank Unit, School of Medical Sciences, Universiti Sains Malaysia, Kubang Kerian, Malaysia, ${ }^{3}$ Department of Biomedicine, School of Health Sciences, Universiti Sains Malaysia, Kubang Kerian, Malaysia,

${ }^{4}$ Department of Oral and Craniofacial Health Sciences, College of Dental Medicine, University of Sharjah, Sharjah, UAE,

${ }^{5}$ Department of Craniofacial Sciences and Oral Biology, School of Dental Sciences, Universiti Sains Malaysia, Kubang Kerian, Malaysia
\end{abstract}

\section{ABSTRACT}

Objective: The objective of this study was to evaluate and compare the two scanning electron microscope (SEM) preparation protocols and determine the better SEM preparation technique to study stem cells on human amniotic membrane (hAM) scaffold. Materials and Methods: Formaldehyde-based protocol and glutaraldehyde-based protocol were compared to evaluate the quality of SEM images for stem cells cultured on hAM scaffold. Results: The results suggested that formaldehyde-based protocol is better than glutaraldehyde-based protocol in terms of showing clearer topography of the membrane as well as the boarders of the cells. To provide intact surface of the SEM sample and avoid possible ruptures of the hAM or the thin cell layer, it is recommended to perform the dehydration step using graded alcohol concentrations of $20 \%, 30 \%, 40 \%, 50 \%, 60 \%$, $70 \%, 80 \%$, and $90 \%$, one time for each and twice in $100 \%$ for 10 min each. Gold sputter-coating step is not recommended as it does not improve the image quality. Conclusions: To obtain clear SEM images, it is recommended to run a preliminary study to determine the better chemicals and conditions of sample preparation even when following preexisting protocols.

Key words: Amniotic membrane, cell attachment, gold sputter-coating, scaffold, scanning electron microscope

\section{INTRODUCTION}

Scanning electron microscope (SEM) is a widely used research tool that produces images of a sample by scanning it with a focused beam of electrons. SEM

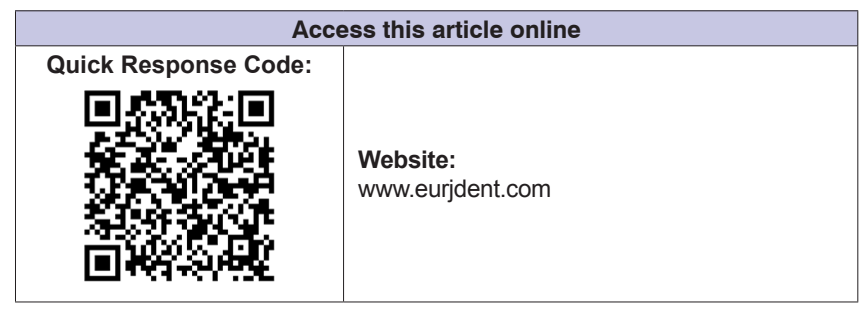

images provide precious information of a sample's surface topography, composition, and properties. The

This is an open access journal, and articles are distributed under the terms of the Creative Commons Attribution-NonCommercial-ShareAlike 4.0 License, which allows others to remix, tweak, and build upon the work non-commercially, as long as appropriate credit is given and the new creations are licensed under the identical terms.

For reprints contact: reprints@medknow.com

How to cite this article: $\mathrm{Al}$ Shehadat $\mathrm{S}$, Gorduysus $\mathrm{MO}$, Abdul Hamid SS, Abdullah NA, Samsudin AR, Ahmad A. Optimization of scanning electron microscope technique for amniotic membrane investigation: A preliminary study. Eur J Dent 2018;12:574-8.

DOI: 10.4103/ejd.ejd_401_17 
correct sample preparation is essential to obtain clear images. SEM samples are required to be completely dry. Thus, biological samples of cells, tissues, and organisms require chemical fixation to preserve and stabilize their structure. This fixation is usually performed using a solution of aldehyde fixative agents such as glutaraldehyde, formaldehyde, and sometimes a combination of both or with other fixatives. ${ }^{[1,2]}$ Most of the formaldehyde are existing as low polymers. The fixation process using formaldehyde takes longer time as the initial binding to protein is not completed before 24 h. ${ }^{[3]}$ Glutaraldehyde has a larger molecule and a faster chemical fixative action due to the presence of more free aldehyde groups (-CHO) ${ }^{[2,4]}$ Additional postfixation is optional and usually performed using osmium tetroxide. ${ }^{[5]}$ Dehydration of the fixed tissues is then required. Air-drying is not recommended for dehydration as it may cause shrinkage and collapse to the fixed tissues. Alternatively, organic solvents such as acetone or ethanol are recommended for samples' dehydration. These solvents replace water in the cells and tissues and thus preserve their structure. Hexamethyldisilazane (HMDS) is finally used for supercritical drying to remove liquid in a precise and controlled way. For electrically nonconductive specimens, sputter coated with gold, gold/palladium alloy, platinum, or other conductive materials is recommended to avoid image artifacts in the SEM images. ${ }^{[6]}$ Alternatively, the samples can be impregnated in osmium to increase the bulk conductivity. ${ }^{[7]}$

Because of its special structure and composition, the amniotic membrane (AM) was nominated as a natural scaffold for tissue regeneration and engineering researches. ${ }^{[8-10]}$ For SEM investigation of AM, most studies have used glutaraldehyde $(2.5 \%$ or $4 \%)$ as a fixative agent, followed by postfixation in osmium tetroxide. Sputter coated with gold was almost always achieved before scanning. ${ }^{[11-14]}$ This study aimed to compare glutaraldehyde-based protocol to formaldehyde-based protocol for the preparation of SEM sample to investigate stem cells cultured on human AM (hAM) scaffold.

\section{MATERIALS AND METHODS}

hAM of size $5 \mathrm{~cm} \times 5 \mathrm{~cm}$ was obtained from Tissue Bank Unit, Universiti Sains Malaysia. Chemical de-epithelialization of hAM was achieved. ${ }^{[15]}$ hAM was cut into $1 \mathrm{~cm} \times 1 \mathrm{~cm}$ and immersed in thermolysin $125 \mu \mathrm{g} / \mathrm{ml}$ (Sigma-Aldrich, USA) up to $25 \mathrm{~min}$ at room temperature. De-epithelialization was evaluated by a light microscope, and brushing technique by a cell scraper (TPP, Europe/Switzerland) was applied when necessary to remove the epithelial cells that could not be washed away by phosphate-buffered saline (PBS). Deciduous teeth stem cells (AllCells, USA) were seeded on the de-epithelialized hAM. All samples were incubated in a humidified atmosphere containing $95 \%$ air and $5 \% \mathrm{CO}_{2}$ at $37^{\circ} \mathrm{C}$ incubator.

After 1-3 days, the samples were washed gently with PBS and fixed either using glutaraldehyde ${ }^{[16]}$ or formaldehyde. ${ }^{[17]}$ In brief, for the formaldehyde technique, the samples were immersed in $4 \%$ paraformaldehyde in $0.1 \mathrm{M}$ phosphate buffer, $\mathrm{pH} 7.4$ for $2 \mathrm{~h}$ at room temperature. Next, they were washed again with PBS and incubated with $8 \%$ formaldehyde at $4^{\circ} \mathrm{C}$. After 2 days, the samples were washed in PBS and dehydrated in graded alcohol of 30\%, 50\%,70\%, $80 \%, 90 \%$, and $100 \%$ (twice), each time for $10 \mathrm{~min}$. For the glutaraldehyde technique, the samples were fixed in $2.5 \%$ glutaraldehyde for $2 \mathrm{~h}$ at $4^{\circ} \mathrm{C}$. Then, the samples were washed in PBS and dehydrated again in a graded alcohol series. Finally, all the samples were incubated in HMDS for $10 \mathrm{~min}$, air-dried in a desiccator, and mounted on suitable size plastic microscope slides [Figure 1]. Some samples were randomly selected to be coated with gold using a sputter coating machine. The samples were then scanned by an SEM (Phenom-World BV, Eindhoven, the Netherlands).

\section{RESULTS}

Cells cultured on hAM were identified in all samples prepared using either formaldehyde or glutaraldehyde, with or without sputter-coated gold. However, it was easier to recognize the cells' bodies and boards as well as the hAM surface topography on the samples prepared using formaldehyde fixative [Figure 2]. Two undesirable features were observed in SEM images. The first was the presence of tears (ruptures) in some

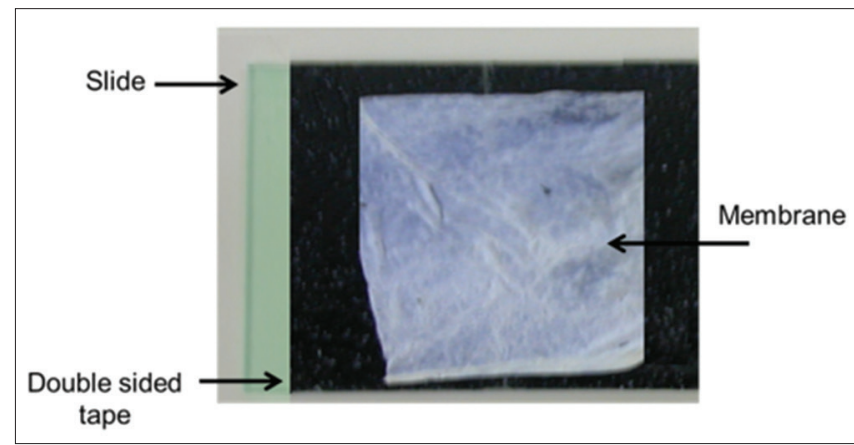

Figure 1: Mounting a human amniotic membrane sample on a plastic slide for scanning electron microscope 
samples. The tears were observed in the cell layer as well as in the membrane [Figure 3]. This feature was observed in both types of samples prepared using either glutaraldehyde or formaldehyde. The second undesirable finding was the presence of small white spots in some images [Figure 4]. This finding was restricted to samples prepared using formaldehyde only. Finally, images from the samples prepared with or without gold spray were compared with priority to noncoated samples.

\section{DISCUSSION}

SEM is a useful tool in tissue engineering studies that provides good details of the morphological changes of cells and cell/scaffold interactions. However, following a suitable protocol for samples, preparation is required to produce images with a good quality. This pilot study was run to analyze and optimize different factors that might affect the quality of SEM images of hAM. The widely used technique to prepare AM for SEM in literature includes the use of glutaraldehyde $(2.5 \%, 3 \%$, or $4 \%$ ) as a fixative agent. ${ }^{[118-20]}$ In these studies, gold sputter coating of samples was traditionally performed after dehydration and drying.

Based on our findings in this study, formaldehyde results in better-quality SEM images when compared to glutaraldehyde as a fixative agent [Figure 2]. The aldehyde group $(-\mathrm{CHO})$ is responsible for the fixative function of the aldehydes as it combines to protein and forms a cross-link- $\mathrm{CH} 2$, called a methylene bridge. ${ }^{[2]}$ The glutaraldehyde molecule has two aldehyde groups. In aqueous solutions, glutaraldehyde is found as large polymers with the presence of free aldehyde groups ($\mathrm{CHO}$ ) of the polymer molecule on the side and the end of each unit. ${ }^{[4]}$ These - $\mathrm{CHO}$ groups can largely contribute in the cross-linking as they combine with any protein they come in contact with. This explains why the chemical reaction of glutaraldehyde with protein is relatively fast (hours) and thus the advantage of rapid fixation of the tissues. ${ }^{[2]}$ Whereas, the formaldehyde has a smaller molecule that dissolves rapidly in water to form methylene hydrate which exists as low polymers in aqueous solutions. Thus, glutaraldehyde has much greater potential for cross-linking when compared to formaldehyde. However, since it is present as larger molecules, its ability to penetrate tissue and biological molecules is less than formaldehyde. Hence, the unclear topography found in our study with glutaraldehyde samples may be interpreted by less penetration of the fixative through the hAM molecule within the
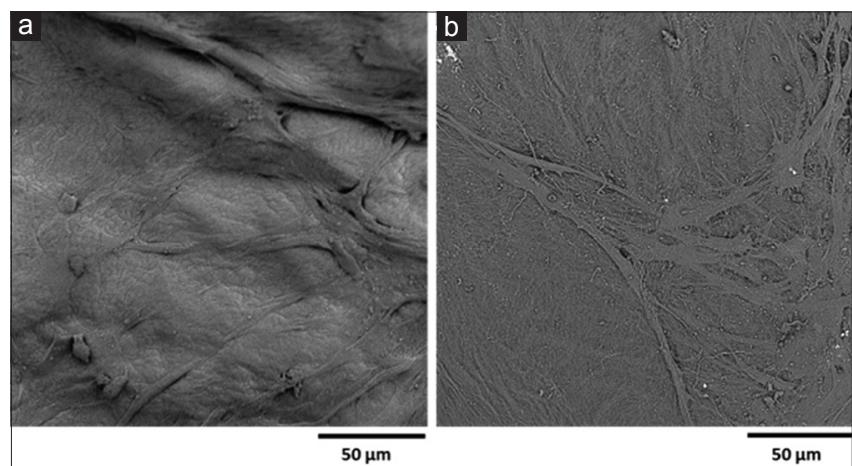

Figure 2: Effect of different fixative material of stem cells seeded on human amniotic membrane for scanning electron microscope analysis. (a) On the specimen fixed using glutaraldehyde, the cells were not recognizable. (b) On the specimen fixed using formaldehyde, the cells were identified on the membrane surface ( $a$ and $b, \times 1000)$
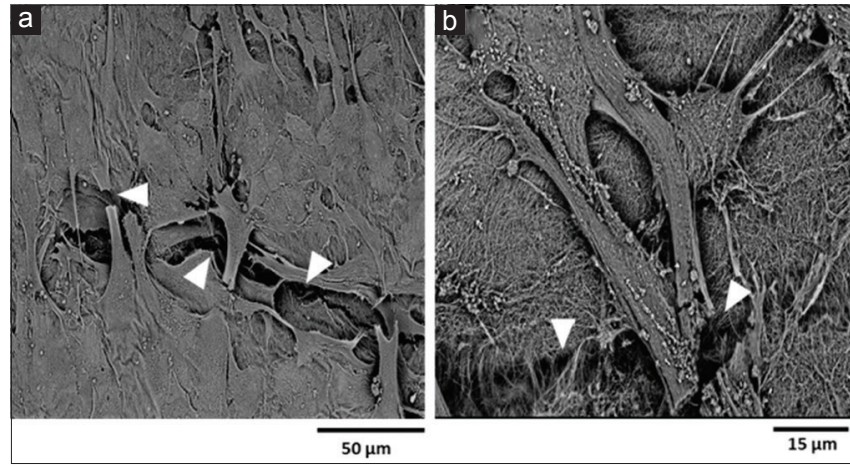

Figure 3: Effects of alcohol dehydration on specimen of stem cells seeded on human amniotic membrane for scanning electron microscope analysis. ( $a$ and $b$ ) Torn layers of cells and membranes were observed (arrows) due to improper dehydration $(a, \times 1000$ and $b, \times 3000)$
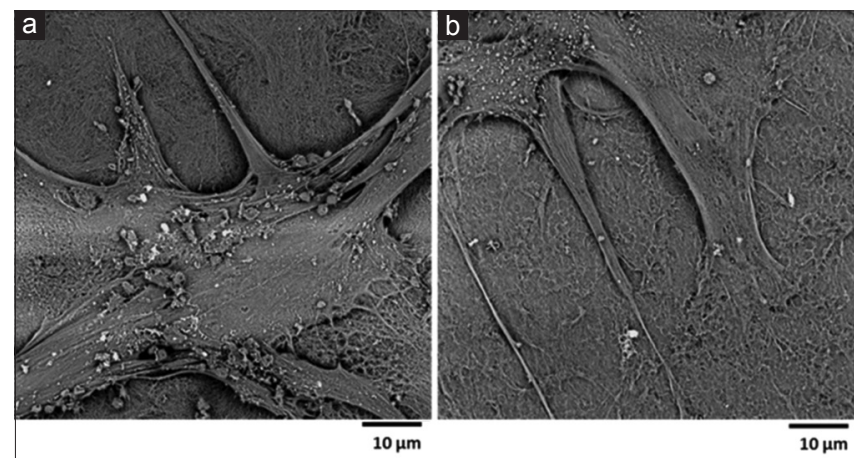

Figure 4: The presence of white spots on the images of specimen of stem cells seeded on human amniotic membrane of scanning electron microscope analysis $(\mathrm{a}$ and $\mathrm{b}, \times 3000)$

used time. To avoid this problem, it is recommended to use glutaraldehyde solution which contains low polymers. This can be achieved using purified glutaraldehyde such as "EM grade" glutaraldehyde (Sigma-Aldrich, USA). ${ }^{[2]}$ The preevaluation of the polymer size of glutaraldehyde available in our laboratory was not considered in this study. 
Torn membrane or ruptured layer of cells was observed in some samples, regardless of the fixative agent used [Figure 3]. This indicates that ruptures in the sample surfaces were not caused by fixative material and were not related to fixation technique. This observation was interpreted as a sever shrinkage of the surface occurred during sample preparation and probably resulted from improper dehydration technique. Thus, a modification of the concentrations of diluted alcohol for the serial dehydration was suggested and tested. The new concentrations of graded alcohol chosen were $20 \%, 30 \%, 40 \%, 50 \%$, $60 \%, 70 \%, 80 \%$ and $90 \%$, one time for each and twice in $100 \%$ for 10 min each. Samples prepared following the new protocol with modified alcohol concentrations showed no torn features [Figure 5].

In some specimens, small, randomly diffused white spots were observed [Figure 4]. These spots were regarded as contamination which occurred during the preparation process probably due to salt crystals of the used buffer. Thus, to eliminate the production of the white spots, it was decided to filter the $4 \%$ paraformaldehyde in $0.1 \mathrm{M}$ phosphate buffer, $\mathrm{pH} 7.4$ solution using $0.20 \mu \mathrm{m}$ sterile filter unit before used. Samples prepared using filtered paraformaldehyde showed no white spots in the SEM image [Figure 5].

Gold sputter coating of hAM specimen was not found to improve the quality of SEM images [Figure $6 a$ and $b$ ].

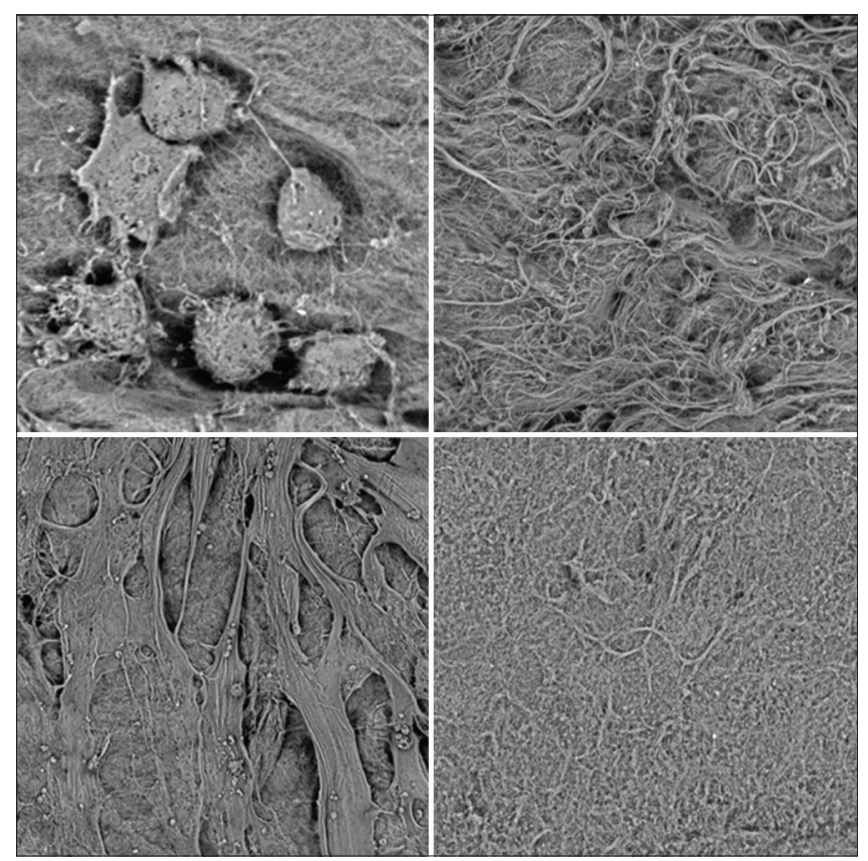

Figure 5: Scanning electron microscope images with different magnification for human amniotic membrane samples prepared with a new protocol adjusted based on the result of the pilot study. White spots and torn layers of cells or membranes were not observed
On contrast, interactions of cells on membrane were shown better in non-sputter-coated specimens. Coating the surface of nonconductive specimen with conductive material is usually indicated to prevent the accumulation of electrostatic charge that may cause scanning faults. Gold sputter coating of AM was routinely achieved in previous SEM studies. ${ }^{[11-14]}$ However, since hAM is a biological specimen, it should be considered as a conductive material. The results of this study suggested that the conductive property of the hAM is sufficient to provide good-quality SEM images and no extra coating is needed. This will save time and cost for SEM preparation.

\section{CONCLUSIONS}

To obtain clear SEM images of AM samples, it is recommended to run a preliminary study to determine the better chemicals and conditions to prepare the samples even if following preexisting protocols. Formaldehyde protocol described in this study is suitable to prepare hAM samples for SEM study. However, it is recommended to filter the paraformaldehyde buffer using $0.20 \mu \mathrm{m}$ sterile filter unit and modify the concentrations of graded alcohol to be $20 \%, 30 \%, 40 \%, 50 \%, 60 \%, 70 \%, 80 \%$, and $90 \%$, one time for each and twice in $100 \%$ for 10 min each. Gold sputter coating of samples is not indicated for hAM specimen prepared for SEM study.

\section{Acknowledgment}

The authors would like to thank the staff of the Sharjah Institute for Medical Researches, University of Sharjah, and Craniofacial Science Laboratory, School of Dental Sciences, Universiti Sains Malaysia, for their cooperation and help.

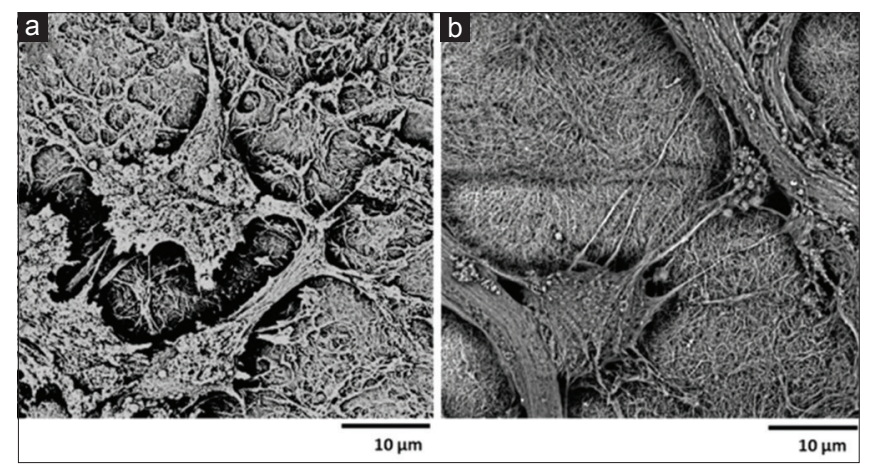

Figure 6: Effects of sputter gold coating on stem cells seeded on human amniotic membrane for scanning electron microscope analysis. Gold sputter-coated specimen (a) did not improve the image of the one without (b). The image of $b$ Showed better interactions of cells on membrane $(\times 5000)$ 


\section{Financial support and sponsorship}

Nil.

\section{Conflicts of interest \\ There are no conflicts of interest.}

\section{REFERENCES}

1. Russell SD, Daghlian CP. Scanning electron microscopic observations on deembedded biological tissue sections: Comparison of different fixatives and embedding materials. Microsc Res Tech 1985;2:489-95.

2. Kiernan JA. Formaldehyde, formalin, paraformaldehyde and glutaraldehyde: What they are and what they do. Microsc Today 2000;1:8-12.

3. Helander KG. Kinetic studies of formaldehyde binding in tissue. Biotech Histochem 1994;69:177-9.

4. Monsan P, Puzo G, Mazarguil H. Mechanism of glutaraldehyde-protein bond formation. Biochimie 1975;57:1281-92.

5. Jeffree CE, Read ND. Ambient-and low-temperature scanning electron microscopy. Electron Microsc Plant Cell 1991. p 313-414.

6. Suzuki E. High-resolution scanning electron microscopy of immunogold-labelled cells by the use of thin plasma coating of osmium. J Microsc 2002;208:153-7.

7. Seligman AM, Wasserkrug HL, Hanker JS. A new staining method (OTO) for enhancing contrast of lipid - Containing membranes and droplets in osmium tetroxide - Fixed tissue with osmiophilic thiocarbohydrazide (TCH). J Cell Biol 1966;30:424-32.

8. Malak TM, Ockleford CD, Bell SC, Dalgleish R, Bright N, Macvicar J, et al. Confocal immunofluorescence localization of collagen types I, III, IV, V and VI and their ultrastructural organization in term human fetal membranes. Placenta 1993;14:385-406.

9. Niknejad H, Peirovi H, Jorjani M, Ahmadiani A, Ghanavi J, Seifalian AM, et al. Properties of the amniotic membrane for potential use in tissue engineering. Eur Cell Mater 2008;15:88-99.

10. Riau AK, Beuerman RW, Lim LS, Mehta JS. Preservation, sterilization and de-epithelialization of human amniotic membrane for use in ocular surface reconstruction. Biomaterials 2010;31:216-25.

11. Koizumi N, Fullwood NJ, Bairaktaris G, Inatomi T, Kinoshita S, Quantock AJ, et al. Cultivation of corneal epithelial cells on intact and denuded human amniotic membrane. Invest Ophthalmol Vis Sci 2000;41:2506-13.

12. Nakamura T, Endo K, Cooper LJ, Fullwood NJ, Tanifuji N, Tsuzuki M, et al. The successful culture and autologous transplantation of rabbit oral mucosal epithelial cells on amniotic membrane. Invest Ophthalmol Vis Sci 2003;44:106-16.

13. Ishino Y, Sano Y, Nakamura T, Connon CJ, Rigby H, Fullwood NJ, et al. Amniotic membrane as a carrier for cultivated human corneal endothelial cell transplantation. Invest Ophthalmol Vis Sci 2004;45:800-6.

14. Nakamura T, Yoshitani M, Rigby H, Fullwood NJ, Ito W, Inatomi T, et al. Sterilized, freeze-dried amniotic membrane: A useful substrate for ocular surface reconstruction. Invest Ophthalmol Vis Sci 2004;45:93-9.

15. Hopkinson A, Shanmuganathan VA, Gray T, Yeung AM, Lowe J, James DK, et al. Optimization of amniotic membrane (AM) denuding for tissue engineering. Tissue Eng Part C Methods 2008;14:371-81.

16. Hwang YC, Kim DH, Hwang IN, Song SJ, Park YJ, Koh JT, et al. Chemical constitution, physical properties, and biocompatibility of experimentally manufactured Portland cement. J Endod 2011;37:58-62.

17. Wiedmann-Al-Ahmad M, Gutwald R, Lauer G, Hübner U Schmelzeisen R. How to optimize seeding and culturing of human osteoblast-like cells on various biomaterials. Biomaterials 2002;23:3319-28

18. Koizumi N, Rigby H, Fullwood NJ, Kawasaki S, Tanioka H, Koizumi K, et al. Comparison of intact and denuded amniotic membrane as a substrate for cell-suspension culture of human limbal epithelial cells. Graefes Arch Clin Exp Ophthalmol 2007;245:123-34.

19. Nakamura T, Sekiyama E, Takaoka M, Bentley AJ, Yokoi N, Fullwood NJ, et al. The use of trehalose-treated freeze-dried amniotic membrane for ocular surface reconstruction. Biomaterials 2008;29:3729-37.

20. Adachi K, Amemiya T, Nakamura T, Honjyo K, Kumamoto S, Yamamoto T, et al. Human periodontal ligament cell sheets cultured on amniotic membrane substrate. Oral Dis 2014;20:582-90. 